\title{
Safety of azithromycin in pediatrics: a systematic review and meta-analysis
}

\author{
Linan Zeng ${ }^{1,2}$ (1) Peipei Xu $\mathrm{u}^{1,2,3,4} \cdot$ Imti Choonara $^{5} \cdot$ Zhenyan Bo $^{1,2} \cdot$ Xiangchen Pan ${ }^{1,2,3,4} \cdot$ Wenyan $\mathrm{Li}^{1,2,3,4}$. \\ Xiaofeng $\mathrm{Ni}^{1,2,3,4} \cdot$ Tao Xiong $^{2,6}$. Can Chen ${ }^{7}$. Leshan Huang ${ }^{8}$ - Shamim Ahmad Qazi ${ }^{9}$ - Dezhi Mu ${ }^{2,6}$ - Lingli Zhang $^{1,2}$
}

Received: 10 December 2019 / Accepted: 6 July 2020 / Published online: 17 July 2020

(C) The Author(s) 2020

\begin{abstract}
Purpose To evaluate the toxicity of azithromycin in neonates, infants, and children.

Methods A systematic review was performed for relevant studies using Medline (Ovid), PubMed, Cochrane Central Register of Controlled Trials, EMBASE, CINAHL, and International Pharmaceutical Abstracts. We calculated the pooled incidence of adverse drug reactions (ADRs) associated with azithromycin based on prospective studies (RCTs and prospective cohort studies) and analyzed the risk difference (RD) of ADRs between azithromycin and placebo or other antibiotics using meta-analysis of RCTs. Results We included 133 studies with 4243 ADRs reported in 197,675 neonates, infants, and children who received azithromycin. The safety of azithromycin as MDA in pediatrics was poorly monitored. The main ADRs were diarrhea and vomiting. In prospective non-MDA studies, the most common toxicity was gastrointestinal ADRs (938/1967; 47.7\%). The most serious toxicities were cardiac (prolonged QT or irregular heart beat) and idiopathic hypertrophic pyloric stenosis (IHPS). Compared with placebo, azithromycin did not show increased risk ADRs based on RCTs (risk difference -0.17 to 0.07 ). The incidence of QT prolonged was higher in the medium-dosage group $(10-30 \mathrm{mg} / \mathrm{kg} / \mathrm{day})$ than that of low-dosage group ( $\leq$ $10 \mathrm{mg} / \mathrm{kg} / \mathrm{day})(82.0 \%$ vs $1.2 \%)$.

Conclusion The safety of azithromycin as MDA needs further evaluation. The most common ADRs are diarrhea and vomiting. The risk of the most serious uncommon ADRs (cardiac-prolonged QT and IHPS) is unknown.
\end{abstract}

Keywords Azithromycin $\cdot$ Safety $\cdot$ Pediatrics $\cdot$ Systematic review $\cdot$ Meta-analysis

Electronic supplementary material The online version of this article (https://doi.org/10.1007/s00228-020-02956-3) contains supplementary material, which is available to authorized users.

Lingli Zhang

zhanglingli@scu.edu.cn

1 Department of Pharmacy/Evidence-based Pharmacy Center, West China Second University Hospital, Sichuan University, Chengdu 610041, China

2 Key Laboratory of Birth Defects and Related Diseases of Women and Children (Sichuan University), Ministry of Education, Chengdu 610041, China

3 West China School of Medicine, Sichuan University, Chengdu 610041, China

4 West China School of Pharmacy, Sichuan University, Chengdu 610041, China
5 Academic Division of Child Health, University of Nottingham, Derbyshire Children's Hospital, Derby DE22 3NE, UK

6 Department of Pediatrics, West China Second University Hospital, Sichuan University, Chengdu 610041, China

7 Department of Pharmacy, Zhongshan Hospital, Fudan University, Shanghai 200032, China

8 Department of Pharmacy, The Third Affiliated Hospital of Guangzhou Medical University, Guangzhou 510150, China

9 Department of Maternal Newborn Child and Adolescent Health, World Health Organization, 20 Avenue Appia, 1211 Geneva, Switzerland 


\section{Introduction}

Azithromycin is an acid-stable orally administered macrolide antimicrobial drug, structurally related to erythromycin [1]. Due to its broad antibacterial spectrum against Streptococcus pneumonia, Moraxella catarrhalis, and atypical pathogens, azithromycin has been used extensively for the treatment of pediatric infectious diseases and became one of the most commonly prescribed antibiotics in children [2-6]. During the last 20 years, azithromycin mass drug administration (MDA) has been used to control trachoma with over 700 million doses of azithromycin being prescribed to children in areas of active trachoma programs [7]. Recent large trials have suggested that periodical azithromycin MDA may reduce post-neonatal infant and child mortality [8]. However, the long-term rationale for mass antibiotic distribution for trachoma is still the subject of debate with concerns of potential toxicity with azithromycin in pediatrics $[9,10]$.

A systematic review that evaluated the tolerance or toxicity of azithromycin in children with asthma found that gastrointestinal adverse reactions such as nausea, diarrhea, and abdominal pain were the main adverse events [11]. Another systematic review of azithromycin use in neonates highlighted the risk of infantile hypertrophic pyloric stenosis (IHPS) [12]. This systematic review aims to evaluate the toxicity of azithromycin both as MDA or non-MDA in neonates, infants, and children from birth to 18 years old. This systematic review was proposed by the World Health Organization (WHO), as one of the systematic reviews in support of developing a guideline of azithromycin use in pediatrics to help national and international policymakers in determining the role of prophylactic azithromycin in reducing child mortality [10].

\section{Methods}

This systematic review conformed to the PRISMA statement and was registered on PROSPERO (CRD 42018112629) [13]. We have reported the methods of literature search, risk of bias assessment, data abstraction, and data analysis in the published protocol [14].

\section{Search strategy and literature search}

In brief, we performed a comprehensive search using Medline (Ovid), PubMed, Cochrane Central Register of Controlled Trials, EMBASE, CINAHL, and International Pharmaceutical Abstracts. We reported the search strategies for each database in the published protocol [14]. We included randomized controlled trials (RCTs), cohort studies, case-control studies, crosssectional studies, case series, and case reports that included pediatric patients (aged from birth to 18 years old) using azithromycin as periodic MDA or as therapeutic agent for any disease till March 2019, and updated the search in September 2019. We had no restriction on language. We excluded editorials, conference abstracts, and reviews. We searched for adverse drug reactions (ADRs) reported in spontaneous reporting systems or safety communication announcements as planned. However, since none of the spontaneous reporting systems provided detailed information for individual ADRs (e.g., age of patient, dosage of azithromycin) and none of the announcements was based on evidence in patients younger than 16 years old, we did not present the result in this paper.

\section{Data extraction and analysis}

We abstracted study design, characteristic of patients, interventions, methods used for safety monitoring, and ADRs from the eligible studies. We used the Cochrane risk of bias tool to assess risk of bias in RCTs, the Newcastle-Ottawa Scale for casecontrol study and cohort studies, and the Joanna Briggs Institute (JBI) Critical Appraisal tools for case series, case reports, and analytical cross-sectional studies [15-17]. We used the Grading of Recommendations Assessment, Development and Evaluation (GRADE) to assess the certainty of body of evidence [18]. We categorized ADRs by systems according to the Medical Dictionary for Regulatory Activities (MedDRA) Terminology (version 21.1) [19] and by frequencies according to the Council for International Organization of Medical Science (CIOMS) as very common $(\geq 10 \%)$, common $(\geq 1 \%$ and $<10 \%)$, uncommon $(\geq 0.1 \%$ and $<1 \%)$, and rare $(<0.1 \%)$ [20]. When the primary study explicitly reported zero ADR or when the study had the capacity to detect the ADR but did not report any event, we counted it as a zero event [21].

We calculated the pooled incidence of ADRs associated with azithromycin based on RCTs and prospective cohort studies to determine the risk of individual ADRs [22, 23]. We categorized ADRs into those that needed specific investigations (e.g., "decreased white blood cells" needs to be detected by a blood test; "prolonged QT" needs to be detected by an electrocardiograph (ECG)) and those that could be observed without specific investigations (e.g., diarrhea, vomiting). We analyzed risk difference (RD) of ADRs between azithromycin and placebo or other antibiotics using meta-analysis of RCTs. We did not use relative risk (RR) or odds ratio (OR) as planned in the protocol, as one cannot use inverse-variance methods to calculate RR or OR, when the number of events is zero in either group. One can, however, still calculate RD [24].

We used chi-square test of contingency table to identify the difference of pooled incidence of ADRs between different dosage groups $(\leq 10 \mathrm{mg} / \mathrm{kg} /$ day, $10-30 \mathrm{mg} / \mathrm{kg} /$ day, $>$ $30 \mathrm{mg} / \mathrm{kg} /$ day). The number of studies in each category did not meet the criteria for conducting regression (at least 10 events per category of dependent variables and 10 events per category of independent variables). 


\section{Results}

Of 10,700 titles identified, 445 proved potentially eligible after reviewing abstracts for the systematic reviews; 131 studies (133 articles) proved eligible following full text review. The updated search until September 2019 found two new trials (three articles) (Fig. 1). ESM Appendix 1 presents the characteristics of eligible studies. Risk of bias of individual RCTs was mainly due to unblinding of participants (high risk or unclear $65.1 \%, 56 / 86$ ) or unblinding of outcome assessment (high risk or unclear 70.9\%, 61/86). Risk of bias of individual cohort studies was mainly due to the lack of demonstration that outcome of interest was not present at the start of the study $(55.9 \%, 19 / 34)$ and the lack of comparability of cohorts $(76.5 \%, 26 / 34)$ (ESM Appendix 2). Among all types of studies, 4243 ADRs were reported from 197,675 pediatric patients who received azithromycin. The majority of ADRs $(56.1 \%, 2382 / 4243)$ were reported from RCTs not as MDA, $14.2 \%$ (603/4261) from retrospective cohort studies, and 6.5\% (274/4243) from prospective cohort studies (Table 1).

\section{Azithromycin as MDA}

We included eight RCTs and one prospective cohort study for azithromycin as MDA. Five RCTs reported no serious ADRs [25-29]. The incidence of ADRs was slightly higher in mass oral azithromycin communities compared with the untreated communities, and the most common ADRs were abdominal pain and vomiting in surveillance for adverse events during a large RCT [30]. The MORDOR study reported 11 cases of
Fig. 1 Flowchart for screened articles

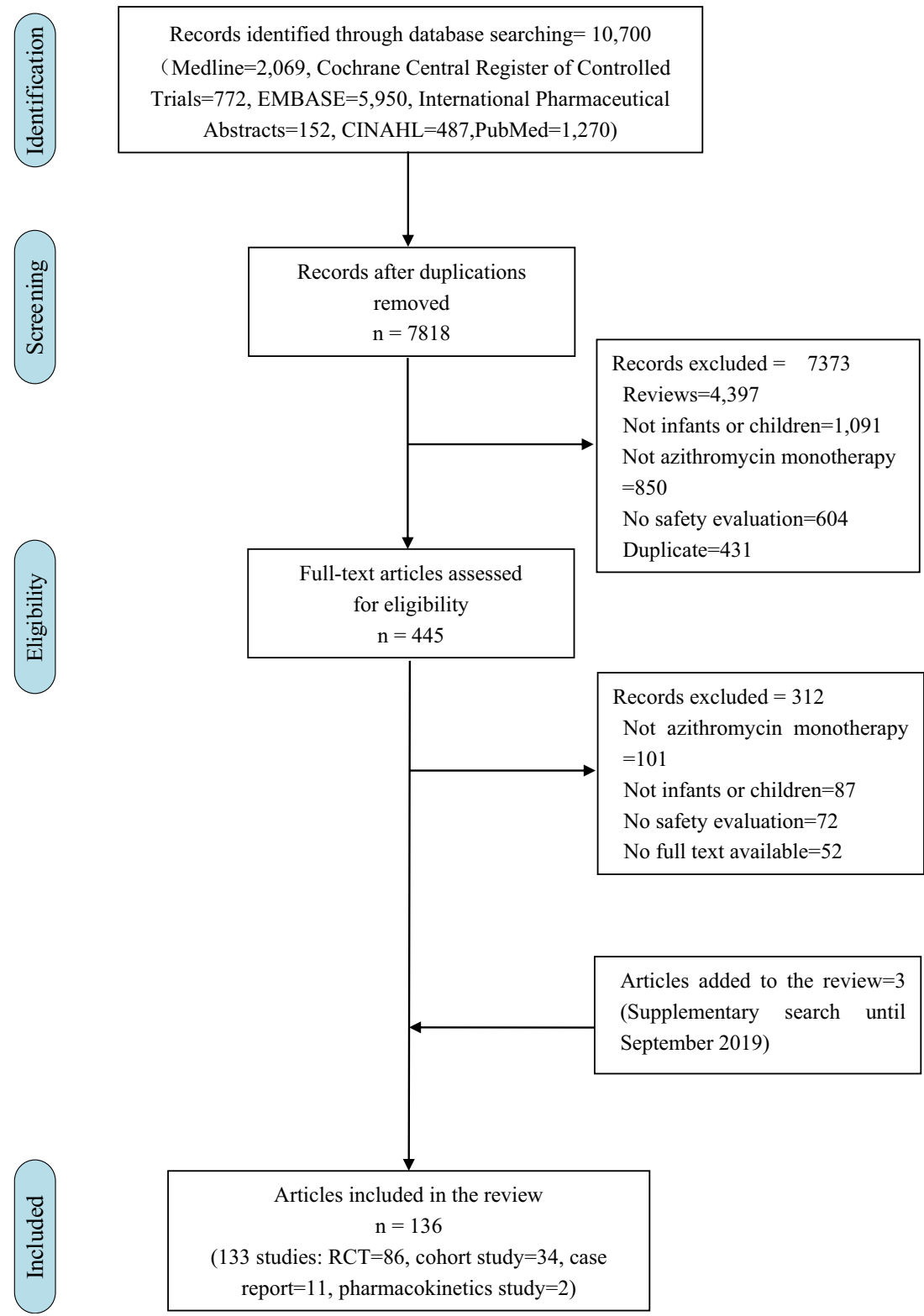


Table 1 Summary of all articles

\begin{tabular}{lcll}
\hline Study type & Number of studies & Number of ADRs (\%) & Number of patients (\%) \\
\hline RCT not as MDA & 77 & $2382(56.1)$ & $9830(5.0)$ \\
Studies of MDA & $10^{*}$ & $948(22.3)$ & $154,180(78.0)$ \\
Prospective cohort & 25 & $274(6.5)$ & $2374(1.2)$ \\
Retrospective cohort & $8^{* *}$ & $603(14.2)$ & $31,209(15.8)$ \\
Case report & 11 & $13(0.3)$ & $12(0.01)$ \\
Pharmacokinetics & 2 & $23(0.5)$ & $70(0.04)$ \\
Total & 133 & 4243 & 197,675 \\
\hline
\end{tabular}

$A D R$, adverse drug reaction; $M D A$, mass drug distribution; $R C T$, randomized controlled trials

*Nine RCTs and one prospective cohort study

**One retrospective cohort study $(n=5039)$ focused on cardiac arrest in pediatric patients receiving azithromycin, and another retrospective cohort study $(n=15,073)$ focused on tendon or joint disorders

serious ADRs including 4 malaria, 1 respiratory infection, 1 ileus, 1 coma, and 4 deaths among 97,047 children through spontaneous reporting system reported by village informants and health facilities [31]. A cluster RCT of biannual mass azithromycin in Niger among preschool children found that the most common guardian-reported ADRs were diarrhea (110/571 in the azithromycin group, 321/1141 in the placebo group, $P=0.03)$, vomiting $(91 / 571$ in the azithromycin group, $240 / 1141$ in the placebo group, $P=0.07)$, and rash $(70 / 571$ in the azithromycin group, $155 / 1141$ in the placebo group, $P=$ 0.07). This study found no statistically significant difference in the incidence of ADRs between azithromycin as MDA and placebo (RR $0.86,95 \%$ CI 0.68 to $1.10, P=0.23$ ) [32, 33]. A pilot cohort study in Ghana reported that 45 out of 14,548 children $(0.3 \%)$ in azithromycin as MDA had mild to moderate self-limiting ADRs including abdominal discomfort, nausea, and vomiting reported by trained volunteers [34].

\section{Azithromycin not as MDA}

\section{Prospective studies}

For azithromycin administered not as MDA, a total of 1967 ADRs were reported in 10,132 patients from 63 RCTs and 22 prospective cohort studies. Gastrointestinal (GI) ADRs were most common, accounting for almost half of the ADRs (938/ $1967,47.7 \%$ ), followed by abnormal investigations (239/ $1967,12.2 \%)$ and respiratory, thoracic, and mediastinal ADRs (186/1967, 9.4\%) (Tables 2 and 3). Diarrhea was the most common event among GI ADRs, accounting for $18.3 \%$ of all ADRs with a risk of 3.56 per 100 patients. Other common ADRs included vomiting (2.56 per 100 patients), abdominal pain (1.37 per 100 patients), and nausea (0.71 per 100 patients) (Tables 2 and 3 ).

Compared with placebo, azithromycin showed no statistically significant difference in terms of incidence of ADRs (risk difference [RD] -0.17 to 0.07 ; low to moderate certainty of evidence) (Fig. 2). Similar results were found when azithromycin was compared with cephalosporins and other macrolides (ESM Appendix 3). Azithromycin showed a decreased risk of diarrhea, when compared with amoxicillin/ clavulanate $(\mathrm{RD}-0.11,95 \% \mathrm{CI}-0.15$ to $-0.07, P<0.001$; low certainty of evidence), but an increased risk of diarrhea when compared with penicillin V (RD 0.03, 95\% CI 0.01 to $0.05, P=0.005$; high certainty of evidence) (ESM Appendix 3). ESM Appendix 4 presents certainty of evidence of each pooled estimate.

\section{Retrospective studies}

Three hundred and six ADRs were reported in 31,221 patients from eight retrospective cohort studies and 11 case report studies (ESM Appendix 1). The ADRs reported in retrospective studies were generally consistent with those in prospective studies. GI ADRs were still the most common events accounting for $44.9 \%$ (145/323) of all ADRs, followed by musculoskeletal and connective tissue ADRs (36.5\%, 118/ 323). However, some ADRs that were not detected in prospective studies were reported by retrospective studies including tendon or joint disorders (TJDs) $(n=118)$, infantile IHPS $(n=8)$, and ventricular tachycardias $(n=4)$. The full list is shown in ESM Appendix 4.

\section{Cardiac toxicity}

Most prospective studies in children did not evaluate the risk of cardiac toxicity. Cardiac toxicity was only studied or reported in eight studies (six prospective, one retrospective, and one case report). Among prospective studies, five RCTs and one prospective cohort study reported 79 cardiac adverse events (Table 4) [35-40]. One prospective study where children received weekly azithromycin for 6 months reported statistically significant QT prolongation [35]. QT prolongation was also noted in two other studies. Two studies reported 
Table 2 Risk of ADRs of azithromycin not as MDA from RCTs and prospective cohort studies (total number of participants $=10,132$ )

\begin{tabular}{|c|c|c|}
\hline ADRs & No. of events & $\begin{array}{l}\text { Pooled incidence of } \\
\text { ADRs per } 100 \text { participants }\end{array}$ \\
\hline
\end{tabular}

Gastrointestinal disorders

Diarrhea

3.56

Vomiting

2.56

Abdominal pain

1.37

Nausea

0.71

Loose stools

0.68

0.19

Abdominal pain upper

0.06

Flatulence

0.06

Stomachache

Subtotal

Cough

0.45

Nasal congestion

0.29

Pharyngolaryngeal pain

Rhinorrhoea

Cough productive

Subtotal

Fever

Fatigue

Subtotal

1.10

subcutaneous tissue disorders

Rash

0.10

Hives

Dermatitis

Fungal dermatitis

0.08

Subtotal

Nervous system disorders

Headache

Dizziness

Somnolence

0.48

$\begin{array}{ll}7 & 0.07\end{array}$

Subtotal

0.06

Metabolism and nutrition disorders

Anorexia

0.22

Decreased appetite

0.10

Subtotal

10

32

Immune system disorders

Jarisch-Herxheimer's reaction

Subtotal

13

1.01
102

1642

Total

We excluded 14 RCTs and 3 prospective cohorts from the calculation of pooled incidences of ADRs due to the lack of detailed description of ADRs

$A D R$, adverse drug reaction; $M D A$, mass drug administrations

*ADRs with pooled incidence less than 5 per 100 participants 
Table 3 Risk of special ADRs of azithromycin not as MDA from RCTs and prospective cohort studies

\begin{tabular}{|c|c|c|c|c|}
\hline ARDs & No. of events & No. of studies & No. of participants & $\begin{array}{l}\text { Pooled incidence } \\
\text { of ARDs per } 100 \\
\text { participants }\end{array}$ \\
\hline \multicolumn{5}{|l|}{ Abnormal investigations } \\
\hline Increased eosinophils & 67 & 52 & 5278 & 1.27 \\
\hline Decreased white blood cells & 52 & 53 & 5360 & 0.97 \\
\hline Decreased neutrophils & 35 & 52 & 5278 & 0.66 \\
\hline Increased glutamic-pyruvic transaminase & 31 & 50 & 5044 & 0.61 \\
\hline Increased aspartate aminotransferase & 11 & 49 & 5009 & 0.22 \\
\hline Thrombocytosis & 9 & 50 & 5120 & 0.18 \\
\hline Abnormal liver function test & 8 & 51 & 5034 & 0.16 \\
\hline Pulmonary function decreased & 14 & 5 & 448 & 3.13 \\
\hline Increased white blood cell counts & 4 & 53 & 5361 & 0.07 \\
\hline Thrombocytopenia & 3 & 50 & 5120 & 0.06 \\
\hline Increased platelet count & 3 & 50 & 5120 & 0.06 \\
\hline Pseudomonas test positive & 2 & 1 & 110 & 1.82 \\
\hline Subtotal & 239 & & & \\
\hline \multicolumn{5}{|l|}{ Cardiac disorders } \\
\hline Electrocardiogram QT prolonged* & 54 & 5 & 277 & 19.49 \\
\hline Electrocardiogram QT shortened & 11 & 4 & 157 & 7.01 \\
\hline Irregular heart beat & 10 & 2 & 157 & 6.37 \\
\hline Elevated heart rate & 4 & 2 & 157 & 2.55 \\
\hline Subtotal & 79 & & & \\
\hline Miscellaneous*** & 7 & 51 & 5154 & 0.14 \\
\hline Total & 325 & & & \\
\hline
\end{tabular}

$A D R$, adverse drug reaction; $M D A$, mass drug administrations; $R C T$, randmised controlled trial

*Including borderline QT

**We excluded 14 RCTs and 3 prospective cohorts from the calculation of pooled incidences of ARDs for the lack of detailed description of ADRs

***ADRs that only has one event reported

irregular heart rates and two studies reported no adverse events. A retrospective cohort study that compared azithromycin $(n=5039)$ with penicillin or cephalosporin $(n=77,943)$ in pediatric patients found that the rate of cardiac arrest in the azithromycin group was lower than that of the penicillin or cephalosporin groups $(0.04 \%$ vs $0.14 \%, P=$ 0.04) [41]. A case report described severe bradyarrhythmia in a 9-month-old infant who received over $50 \mathrm{mg} / \mathrm{kg}$ azithromycin intravenously over $20 \mathrm{~min}$ [42].

\section{Pyloric stenosis}

A retrospective cohort study utilized a large health system database and evaluated 1,074,236 children born over a period of 12 years [43]; 2466 infants developed IHPS and 4875 infants received azithromycin in the first 90 days of life and eight of these infants (all boys) developed IHPS. The study demonstrated an increased risk following exposure to azithromycin in the first 2 weeks of life (adjusted OR [aOR] of 8.26, 95\% CI 2.62-26.0) [43]. Azithromycin exposure between 15 and 42 days also increased the risk of IHPS (aOR of $2.98,95 \%$ CI $1.24-7.20$ ).

\section{Subgroup analysis of dosage}

The incidence of diarrhea, vomiting, fever, and rash was higher in the high-dosage group compared with the low- or medium-dosage group $(P<0.01)$ (Table 5). The incidence of prolonged QT and increased eosinophils was higher in the medium-dosage group than in the low-dosage group $(P<0.01)$ (Table 5).

\section{Discussion}

Our review found that the main toxicity of azithromycin in pediatrics was gastrointestinal toxicity, specifically diarrhea, vomiting, and abdominal pain. Based on available data, the 


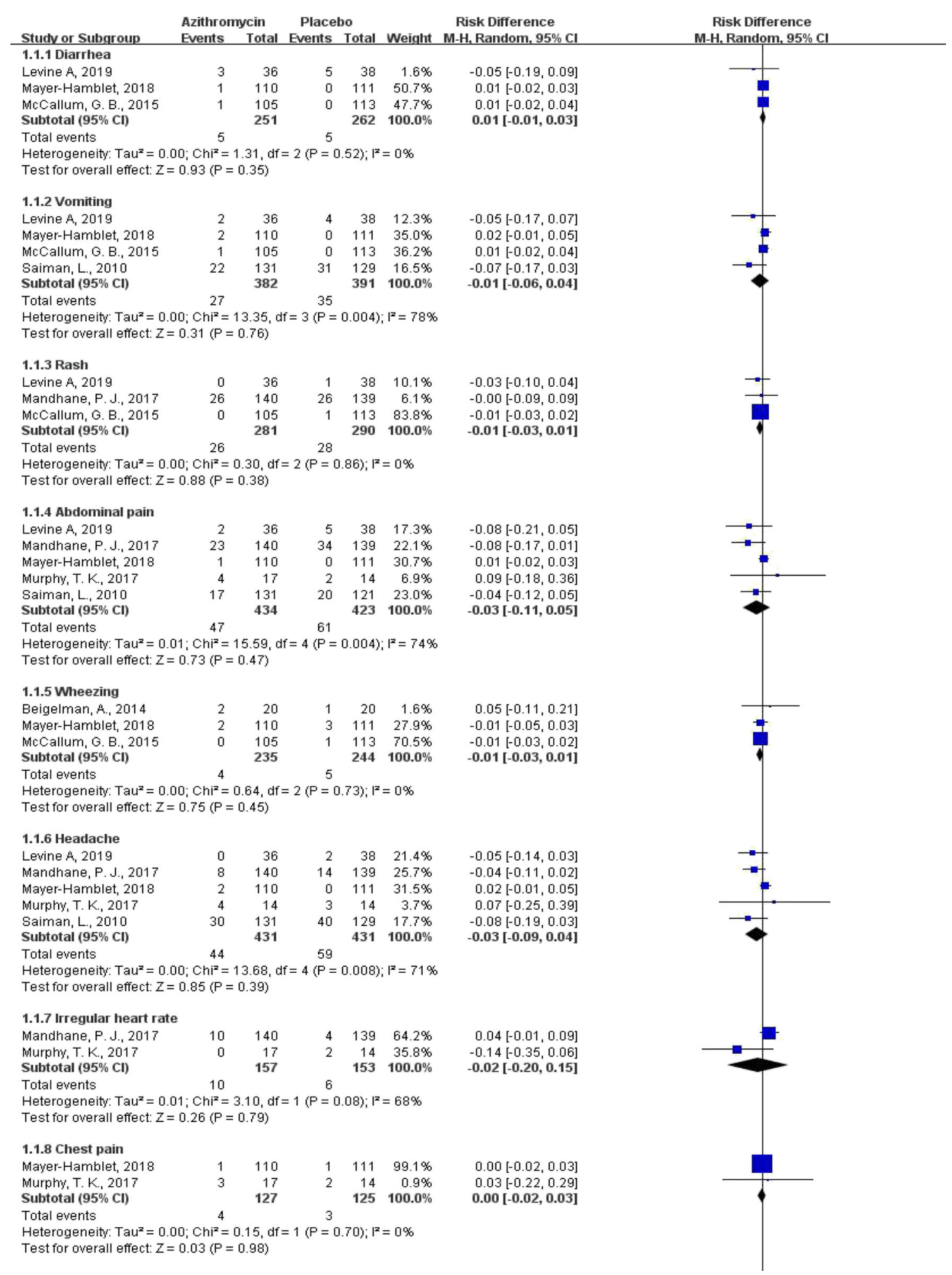

Fig. 2 Risk difference of ADRs between azithromycin not as MDA and placebo

main ADRs of azithromycin as MDA were diarrhea and vomiting. However, the reporting of ADRs in RCTs of MDA was very variable. Concerns about the reporting of ADRs in RCTs involving children have been reported by several groups [44, 45]. For azithromycin not as MDA, our review highlighted that the most common toxicity was GI adverse reactions, and the most serious toxicities were cardiac adverse reactions and IHPS. The risk of cardiac toxicity and IHPS following MDA is unknown and can only be determined by prospective surveillance studies. The dose of 
1.1.9 Constipation

Mayer-Hamblet, 2018

Murphy, T. K., 2017

Subtotal $(95 \% \mathrm{Cl})$

Total events

Heterogeneity: $\operatorname{Tau}^{2}=0.14 ; \mathrm{Chi}^{2}=17.49, \mathrm{df}=1(\mathrm{P}<0.0001) ; \mathrm{I}^{\mathbf{2}}=94 \%$

Test for overall effect: $Z=0.62(P=0.54)$

1.1.10 Decreased appetite

Murphy, T. K., 2017

Subtotal $(95 \% \mathrm{Cl})$

Total events

Heterogeneity: $\operatorname{Tau}^{2}=0.00 ; \mathrm{Chi}^{2}=1.52, \mathrm{df}=1(\mathrm{P}=0.22) ;\left.\right|^{2}=34 \%$

Test for overall effect: $Z=0.15(P=0.88)$

1.1.11 Elevated heart rates

Murphy, T. K., 2017

Subtotal $(95 \% \mathrm{CI})$

Total events

$\begin{array}{rr}0 & 140 \\ 4 & 17 \\ & 157\end{array}$

$\begin{array}{rr}139 & 57.5 \% \\ 14 & 42.5 \% \\ 153 & 100.0 \%\end{array}$

4

Heterogeneity: $\operatorname{Tau}^{2}=0.04 ; \mathrm{Chi}^{2}=6.65, \mathrm{df}=1(\mathrm{P}=0.010) ; \mathrm{I}^{2}=85 \%$

Test for overall effect: $Z=0.44(P=0.66)$

\subsubsection{QT prolonged}

Levine A, 2019

Mayer-Hamblet, 2018

Murphy, T. K., 2017

Subtotal $(95 \% \mathrm{CI})$

Total events

$\begin{array}{rrrrr}0 & 35 & 0 & 38 & 48.1 \% \\ 2 & 110 & 7 & 111 & 48.8 \% \\ 2 & 17 & 1 & 14 & 3.1 \% \\ & \mathbf{1 6 2} & & \mathbf{1 6 3} & \mathbf{1 0 0 . 0} \% \\ 4 & & 8 & & \end{array}$

Heterogeneity: $\operatorname{Tau}^{2}=0.00 ; \mathrm{Chi}^{2}=1.96, \mathrm{df}=2(\mathrm{P}=0.38) ;\left.\right|^{2}=0 \%$

Test for overall effect: $Z=1.11(P=0.27)$

1.1.13 Cough

Mayer-Hamblet, 2018

$\begin{array}{rrrrr}8 & 110 & 12 & 111 & 52.2 \% \\ 63 & 131 & 91 & 129 & 47.8 \% \\ & \mathbf{2 4 1} & & \mathbf{2 4 0} & \mathbf{1 0 0 . 0} \%\end{array}$

Saiman, L., 2010

Subtotal $(95 \% \mathrm{Cl})$

Total events 71 103

Heterogeneity: Tau $^{2}=0.02 ; \mathrm{Chi}^{2}=9.20, \mathrm{df}=1(\mathrm{P}=0.002) ; \mathrm{I}^{2}=89 \%$

Test for overall effect: $Z=1.17(P=0.24)$

1.1.14 Neutrophil count decreased

$\begin{array}{lrrrrr}\text { Mayer-Hamblet, 2018 } & 1 & 110 & 0 & 111 & 24.1 \% \\ \text { McCallum, G. B., 2013 } & 0 & 50 & 0 & 47 & 9.5 \% \\ \text { Saiman, L., 2010 } & 0 & 131 & 0 & 129 & 66.4 \% \\ \text { Subtotal (95\% CI) } & & 291 & & \mathbf{2 8 7} & \mathbf{1 0 0 . 0} \% \\ \text { Total events } & 1 & & 0 & & \end{array}$

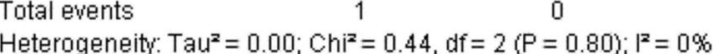

Test for overall effect: $Z=0.35(P=0.72)$

1.1.15 Nasal congestion

Mayer-Hamblet, 2018

Saiman, L., 2010

$\begin{array}{rrrrr}1 & 110 & 0 & 111 & 95.5 \% \\ 45 & 131 & 42 & 129 & 4.5 \% \\ & \mathbf{2 4 1} & & \mathbf{2 4 0} & \mathbf{1 0 0 . 0} \%\end{array}$

Total events 46 42

Heterogeneity: Tau $^{2}=0.00 ;$ Chi $^{2}=0.15, \mathrm{df}=1(\mathrm{P}=0.70) ;\left.\right|^{2}=0 \%$

Test for overall effect: $Z=0.77(P=0.44)$

\subsubsection{Fever}

Levine A, 2019

Mayer-Hamblet, 2018

Saiman, L., 2010

Subtotal $(95 \% \mathrm{CI})$

$\begin{array}{rr}2 & 36 \\ 4 & 110 \\ 30 & 131 \\ & 277\end{array}$

Total events

36

Heterogeneity: Tau $^{2}=0.01 ; \mathrm{Chi}^{2}=11.82, \mathrm{df}=2(\mathrm{P}=0.003) ;\left.\right|^{2}=83 \%$

Test for overall effect: $Z=0.04(P=0.97)$
$0.00[-0.02,0.03]$

$-0.36[-0.61,-0.10]$

$-0.17[-0.70,0.37]$

$0.01[-0.02,0.03]$

$-0.10[-0.36,0.17]$

$-0.01[-0.13,0.11]$

$0.00[-0.01,0.01]$

$0.16[-0.08,0.41]$

$0.07[-0.24,0.38]$

$0.00[-0.05,0.05]$

$-0.04[-0.10,0.01]$

$0.05[-0.16,0.25]$

$-0.02[-0.06,0.02]$

$-0.04[-0.11,0.04]$

$-0.22[-0.34,-0.11]$

$-0.13[-0.34,0.08]$

$0.01[-0.02,0.03]$

$0.00[-0.04,0.04]$

$0.00[-0.01,0.01]$

$0.00[-0.01,0.01]$

$0.01[-0.02,0.03]$

$0.02[-0.10,0.13]$

0.01 [-0.01, 0.03]

$.03[-0.06,0.12]$

$0.04[-0.00,0.08]$

$-0.09[-0.20,0.02]$

$-0.00[-0.11,0.11]$
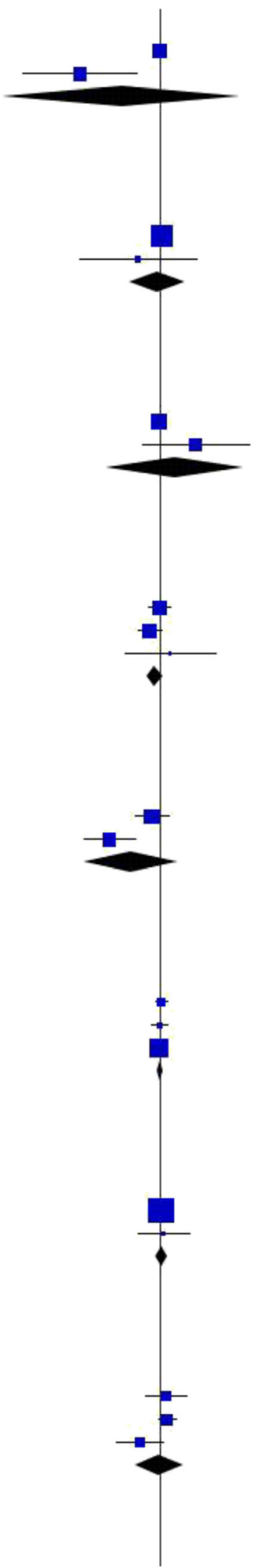

Fig. 2 (continued) 


\begin{abstract}
1.1.17 Rhinorrhea Mayer-Hamblet, 2018 Saiman, L., 2010 Subtotal $(95 \% \mathrm{CI})$

Total events

Heterageneity: $\operatorname{Tau}^{2}=0.02 ; \mathrm{Chi}^{2}=12.06, \mathrm{df}=1(\mathrm{P}=0.0005) ; \mathrm{I}^{2}=92 \%$

Test for overall effect: $Z=0.49(P=0.62)$

\subsubsection{Productive cough}

Maver-Hamblet 2018

Saiman, L., 2010

Subtotal $(95 \% \mathrm{CI})$

Total events

Heterogeneity: $\operatorname{Tau}^{2}=0.02 ; \mathrm{Chi}^{2}=27.55, \mathrm{df}=1(\mathrm{P}<0.00001) ; \mathrm{I}^{2}=96 \%$

Test for overall effect: $Z=0.43(P=0.67)$

\subsubsection{Fatigue}

Mayer-Hamblet, 2018

Saiman, L., 2010

Subtotal $(95 \% \mathrm{Cl})$

Total events

Heterogeneity: $\operatorname{Tau}^{2}=0.00 ; \mathrm{Chi}^{2}=3.40, \mathrm{df}=1(\mathrm{P}=0.07) ; \mathrm{I}^{2}=71 \%$

Test for overall effect: $Z=0.21(P=0.84)$

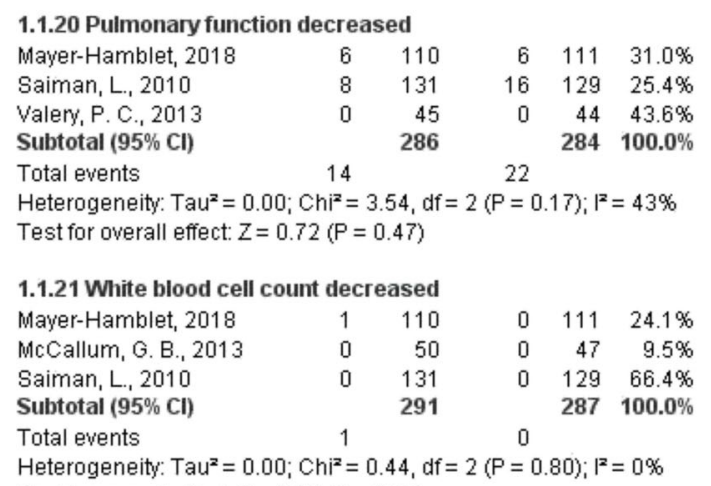

Test for overall effect: $Z=0.35(P=0.72)$
\end{abstract}

Test for subaroun differences: $\mathrm{Ch}^{2}=8.64 . \mathrm{df}=20(\mathrm{P}=0.99) . \mathrm{I}^{\mathrm{p}}=0 \%$

Fig. 2 (continued)

azithromycin was associated with the risk of ADRs. The higher the dosage, the higher the risk of an ADR.

Our study has several strengths. Using rigorous systematic review methods, we did a comprehensive search of the literature and evaluated the safety of azithromycin as both MDA and not as MDA. Our review included recently published studies which were not included in prior reviews, and thus, summarized all of the available evidence, providing optimal insight into the safety of azithromycin in pediatrics. We assessed the risk of bias of each primary study using risk of bias assessment tools based on study design. We detected the incidence of adverse events based on prospective studies from which the data are more reliable, and explored uncommon events from the larger retrospective studies.

This review also has some limitations. First, the ADRs were poorly reported in primary studies which led to the probable underestimate of the incidence of ADRs in this review. Even the meta-analysis might still be underpowered to detect potential differences between azithromycin and placebo or
$-0.01[-0.03,0.02]$

$-0.09[-0.19,0.01]$

$-0.05[-0.23,0.14]$

$0.01[-0.02,0.03]$

$-0.11[-0.19,-0.03]$

$-0.05[-0.27,0.17]$

(1)

$0.01[-0.02,0.03]$

$-0.03[-0.10,0.04]$

$-0.01[-0.07,0.06]$

$0.00[-0.06,0.06]$
$-0.06[-0.13,0.01]$
$0.00[-0.04,0.04]$
$-0.02[-0.06,0.03]$

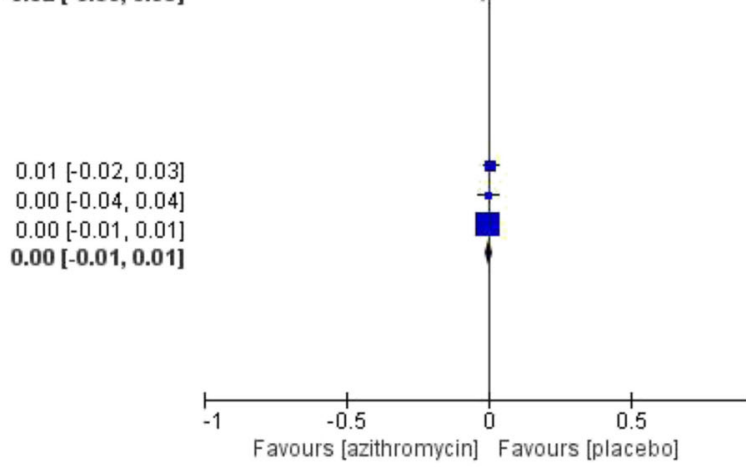

$0.00[-0.01,0.01]$

Favours [azithromycin] Favours [placebo]

other antibiotics. The lack of ADR reporting is more common in studies of azithromycin as MDA and we were unable to conclude the safety of azithromycin as MDA compared with placebo. Second, we did not perform analysis of different age groups as planned in the protocol since most primary studies did not report the outcomes for each age group separately.

To our knowledge, the ADRs of azithromycin as MDA in children have not been evaluated in previous systematic reviews [46]. For azithromycin not as MDA, cardiac toxicity of azithromycin has been a concern for a long time. Previous studies and reviews found the risk of azithromycin appears to depend on age and prior cardiovascular risk in adults. However, none of them evaluated the risk in pediatric patients. In our review, cardiac adverse events were found in pediatric patients, but the difference between the azithromycin group and the control group was not significant in most of the studies. Only one study found a statistically significant increase in QT prolongation, but this study involved weekly administration of azithromycin for 6 months and only children who 


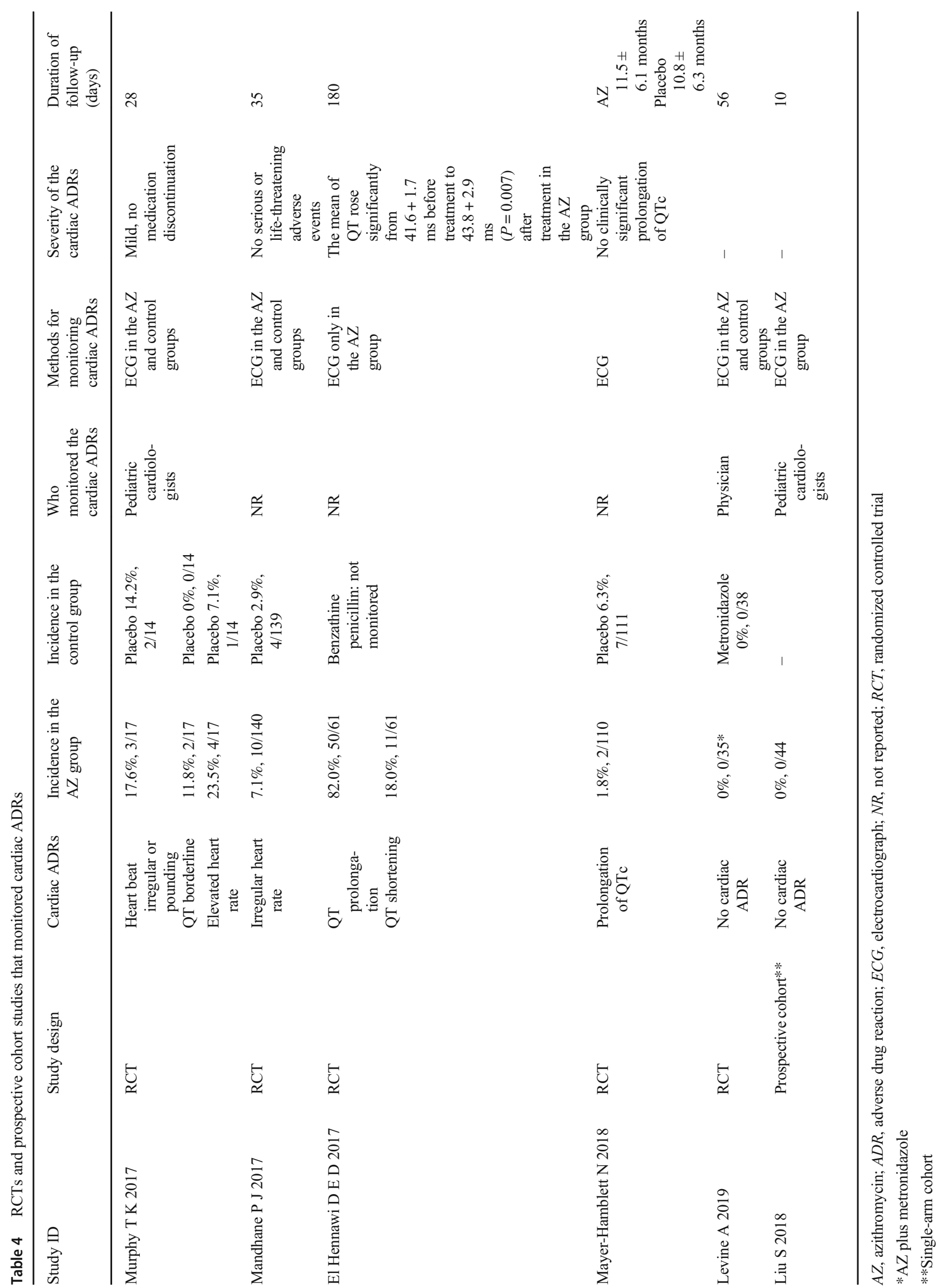


Table 5 Pooled incidence of ADRs from RCTs and prospective cohort studies in different dose groups

\begin{tabular}{|c|c|c|c|c|}
\hline ADRs & Low dosage $(\leq 10 \mathrm{mg} / \mathrm{kg})$ & $\begin{array}{l}\text { Medium dosage } \\
(10-30 \mathrm{mg} / \mathrm{kg})\end{array}$ & $\begin{array}{l}\text { High dosage } \\
(>30 \mathrm{mg} / \mathrm{kg})\end{array}$ & $P$ value \\
\hline \multicolumn{5}{|c|}{ ADRs that did not need specific investigations* } \\
\hline Diarrhea & $147(2.5 \%)^{\mathrm{a}}$ & $85(3.5 \%)^{\mathrm{a}}$ & $42(9.3 \%)^{\mathrm{b}}$ & $<0.001$ \\
\hline Vomiting & $113(1.9 \%)^{\mathrm{a}}$ & $65(2.6 \%)^{\mathrm{a}}$ & $48(10.7 \%)^{\mathrm{b}}$ & $<0.001$ \\
\hline Abdominal pain & $98(1.7 \%)^{\mathrm{a}}$ & $28(1.1 \%)^{\mathrm{a}}$ & $11(2.4 \%)^{\mathrm{a}}$ & 0.059 \\
\hline Fever & $9(0.2 \%)^{\mathrm{a}}$ & $0(0.0 \%)^{\mathrm{a}}$ & $7(1.6 \%)^{\mathrm{b}}$ & $<0.001$ \\
\hline Rash & $73(1.3 \%)^{\mathrm{a}}$ & $15(0.6 \%)^{\mathrm{b}}$ & $23(5.1 \%)^{\mathrm{c}}$ & $<0.001$ \\
\hline \multicolumn{5}{|c|}{ ADRs that needed specific investigation } \\
\hline QT prolonged $^{\alpha}$ & $4(1.2 \%)^{\mathrm{a}}$ & $50(82.0 \%)^{\mathrm{b}}$ & - & $<0.001$ \\
\hline Pulmonary function decreased ${ }^{\beta}$ & $14(4.3 \%)^{\mathrm{a}}$ & $0(0.0 \%)^{\mathrm{a}}$ & - & 0.10 \\
\hline Increased eosinophil ${ }^{\gamma}$ & $38(0.9 \%)^{\mathrm{a}}$ & $31(3.0 \%)^{\mathrm{b}}$ & - & $<0.001$ \\
\hline
\end{tabular}

There was no statistical difference between the two groups with the same letter a, b, or $\mathrm{c}$ in the following table. Otherwise, there is a statistical difference $A D R$, adverse drug reaction; $R C T$, randomized controlled trial

*The total number of patients was 5811 in the low-dosage group, 2454 in the medium-dosage group, and 450 in the high-dosage group

received azithromycin received ECGs [35]. Additionally, the data from some studies must be questioned because the method for safety surveillance was poorly reported [26, 27, 35]. Future studies in pediatric patients should be conscious of using robust methods for safety monitoring.

Previous studies have demonstrated the association between erythromycin exposure early in life and IHPS [47-52]. Only one retrospective study was found in our review that evaluated the association between azithromycin and IHPS. Since azithromycin and erythromycin are slightly different in molecular structure, further studies are required to determine the relationship between early exposure to azithromycin in life and IHPS [12]. The risk of IHPS following MDA is unknown and should be considered in future studies of MDA. However, prospective surveillance following MDA with larger numbers of patients is more likely to be beneficial.

\section{Conclusion}

The main ADRs of azithromycin whether used as MDA or not were gastrointestinal, specifically diarrhea, abdominal pain, and vomiting. For azithromycin not as MDA, the most serious toxicities were cardiac adverse reactions and IHPS. Increasing dose proved to increase the risk of ADRs.

Author contributions IC, LNZ, PPE, LLZ, TX, and SAQ designed the study. XCP, WYL, PPX, and XFN screened the literatures independently in two pairs. PPX, XCP, WYL, PPX, XFN, CC, and LSH abstracted data and cross-checked the data in pairs. LNZ and TX resolved discrepancies in literature screening and data abstraction. ZYB, LNZ, and PPX analyzed the data. LZN, PPX, and IC interpreted the data. LNZ, IC, TX, SAQ, DZM, and LLZ drafted the work or revised it critically for important intellectual content and have given final approval of the version published. All authors agree to be accountable for all aspects of the work in ensuring that questions related to the accuracy or integrity of any part of the work are appropriately investigated and resolved.

Funding information This project was funded by the Department of Maternal, Newborn, Child and Adolescent Health of World Health Organization (WHO Registration 2018/859230-0) and Key Program of Science and Technology Agency, Sichuan Province (No. 2017JY0067).

\section{Compliance with ethical standards}

Conflict of interest The authors declare that they have no conflict of interest.

Open Access This article is licensed under a Creative Commons Attribution 4.0 International License, which permits use, sharing, adaptation, distribution and reproduction in any medium or format, as long as you give appropriate credit to the original author(s) and the source, provide a link to the Creative Commons licence, and indicate if changes were made. The images or other third party material in this article are included in the article's Creative Commons licence, unless indicated otherwise in a credit line to the material. If material is not included in the article's Creative Commons licence and your intended use is not permitted by statutory regulation or exceeds the permitted use, you will need to obtain permission directly from the copyright holder. To view a copy of this licence, visit http://creativecommons.org/licenses/by/4.0/.

\section{References}

1. Peters DH, Friedel HA, McTavish D (1992) Azithromycin. Drugs 44:750-799

2. Laopaiboon M, Panpanich R, Swa MK (2015) Azithromycin for acute lower respiratory tract infections. Cochrane Database Syst Rev 8:CD001954

3. Clavenna A, Bonati M (2011) Differences in antibiotic prescribing in paediatric outpatients. Arch Dis Child 96:590-595

4. Franchi C, Sequi M, Bonati M, Nobili A, Pasina L, Bortolotti A, Fortino I, Merlino L, Clavenna A (2011) Differences in outpatient 
antibiotic prescription in Italy's Lombardy region. Infection 39: 299-308

5. Grijalva CG, Nuorti JP, Griffin MR (2009) Antibiotic prescription rates for acute respiratory tract infections in US ambulatory settings. JAMA 302:758-766

6. Langtry HD, Balfour JA (1998) Azithromycin. A review of its use in paediatric infectious diseases. Drugs 56:273-297

7. Emerson PM, Hooper PJ, Sarah V (2017) Progress and projections in the program to eliminate trachoma. PLoS Negl Trop Dis 11: $\mathrm{e} 0005402$

8. Keenan JD, Bailey RL, West SK, Arzika AM, Hart J, Weaver J, Kalua K, Mrango Z, Ray KJ, Cook C, Lebas E, O'Brien KS, Emerson PM, Porco TC, Lietman TM, MORDOR Study Group (2018) Azithromycin to reduce childhood mortality in subSaharan Africa. N Engl J Med 378:1583-1592

9. Gaynor BD, Yi E, Lietman T (2002) Rationale for mass antibiotic distribution for trachoma elimination. Int Ophthalmol Clin 42:8592

10. World Health Organization. Presumptive use of azithromycin. Guideline in development. Available at: https://www.who.int/ maternal_child_adolescent/guidelines/development/provision-ofazithromycin-to-infants/en/. Accessed 10 Feb 2020

11. Tian BP, Xuan N, Wang Y, Zhang G, Cui W (2019) The efficacy and safety of azithromycin in asthma: a systematic review. J Cell Mol Med 23:1638-1646

12. Smith C, Egunsola O, Choonara I, Kotecha S, Jacqz-Aigrain E, Sammons H (2015) Use and safety of azithromycin in neonates: a systematic review. BMJ Open 5:e08194

13. Liberati A, Altman DG, Tetzlaff J, Mulrow C, Gotzsche PC, Ioannidis JPA, Clarke M, Devereaux PJ, Kleijnen J, Moher D (2009) The PRISMA statement for reporting systematic reviews and meta-analyses of studies that evaluate healthcare interventions: explanation and elaboration. BMJ 339:b2700

14. Xu P, Zeng L, Xiong T, Choonara I, Qazi S, Zhang L (2019) Safety of azithromycin in paediatrics: a systematic review protocol. BMJ Paediatr Open 3:e00469

15. Higgins J, Green S (2011) Cochrane handbook for systematic reviews of interventions. The Cochrane Library, Wiley, Chichester

16. Wells GA, Shea B, O'Connell D et al (2011) The NewcastleOttawa Scale (NOS) for assessing the quality if nonrandomized studies in meta-analyses. Available at: http://www.ohri.ca/ programs/clinical_epidemiology/oxford.asp. Accessed 16 Jul 2020

17. Joanna Briggs Institute. Critical appraisal tools. Available at: https://joannabriggs.org/ebp/critical appraisal tools. Accessed 16 Jul 2020

18. Guyatt G, Oxman AD, Akl EA et al (2011) GRADE guidelines: 1 . Introduction - GRADE evidence profiles and summary of findings tables. J Clin Epidemiol 64:382-394

19. Brown EG, Wood L, Wood S (1999) The medical dictionary for regulatory activities (MedDRA). Drug Saf 20:109-117

20. Neubert A, Dormann H, Prokosch HU, Bürkle T, Rascher W, Sojer R, Brune K, Criegee-Rieck M (2013) E-pharmacovigilance: development and implementation of a computable knowledge base to identify adverse drug reactions. Br J Clin Pharmacol 76(Suppl 1): 69-77

21. Cortese S (2016) Guidance on conducting systematic reviews and meta-analyses of completed comparative pharmacoepidemiological studies of safety outcomes: the gap is now filled. Epidemiol Psychiatr Sci 25:425-427

22. Egunsola O, Choonara I, Sammons HM (2015) Safety of lamotrigine in paediatrics: a systematic review. BMJ Open 5: $\mathrm{e} 007711$

23. Egunsola O, Choonara I, Sammons HM (2016) Safety of levetiracetam in paediatrics: a systematic review. PlosOne 11:e0149686

24. Efthimiou O (2018) Practical guide to the meta-analysis of rare events. Evid Based Mental Health 21:72-76
25. Amza A, Kadri B, Nassirou B, Stoller NE, Yu SN, Zhou Z, West SK, Mabey DCW, Bailey RL, Keenan JD, Porco TC, Lietman TM, Gaynor BD (2013) A cluster-randomized controlled trial evaluating the effects of mass azithromycin treatment on growth and nutrition in Niger. Am J Trop Med Hyg 88:138-143

26. West SK, Bailey R, Munoz B, Edwards T, Mkocha H, Gaydos C, Lietman T, Porco T, Mabey D, Quinn TC (2013) A randomized trial of two coverage targets for mass treatment with azithromycin for trachoma. PLoS Negl Trop Dis 7:e2415

27. Melese M, Alemayehu W, Lakew T, Yi E, House J, Chidambaram JD, Zhou Z, Cevallos V, Ray K, Hong KC, Porco TC, Phan I, Zaidi A, Gaynor BD, Whitcher JP, Lietman TM (2008) Comparison of annual and biannual mass antibiotic administration for elimination of infectious trachoma. JAMA 299:778-784

28. O'Brien KS, Cotter SY, Amza A et al (2018) Childhood mortality after mass distribution of azithromycin: a secondary analysis of the PRET cluster-randomized trial in Niger. Pediatr Infect Dis J 37: 1082-1086

29. Keenan JD, Gebresillasie S, Stoller NE, Haile BA, Tadesse Z, Cotter SY, Ray KJ, Aiemjoy K, Porco TC, Callahan EK, Emerson PM, Lietman TM (2019) Linear growth in preschool children treated with mass azithromycin distributions for trachoma: a cluster-randomized trial. PLoS Negl Trop Dis 13:e0007442

30. Ayele B, Gebre T, House JI et al (2011) Adverse events after mass azithromycin treatments for trachoma in Ethiopia. Am J Trop Med Hyg 85:291-294

31. Keenan JD, Tadesse Z, Gebresillasie S, Shiferaw A, Zerihun M, Emerson PM, Callahan K, Cotter SY, Stoller NE, Porco TC, Oldenburg CE, Lietman TM (2018) Mass azithromycin distribution for hyperendemic trachoma following a cluster-randomized trial: a continuation study of randomly reassigned subclusters (TANA II). PLoS Med 15:e1002633

32. Oldenburg CE, Arzika AM, Maliki R, Kane MS, Lebas E, Ray KJ, Cook C, Cotter SY, Zhou Z, West SK, Bailey R, Porco TC, Keenan JD, Lietman TM, MORDOR Study Group (2018) Safety of azithromycin in infants under six months of age in Niger: a community randomized trial. PLoS Negl Trop Dis 12:e0006950

33. Arzika AM, Maliki R, Boubacar N, Kane S, Cotter SY, Lebas E, Cook C, Bailey RL, West SK, Rosenthal PJ, Porco TC, Lietman TM, Keenan JD, for the MORDOR Study Group (2019) Biannual mass azithromycin distributions and malaria parasitemia in preschool children in Niger: a cluster-randomized, placebo controlled trial. PLoS Med 16:e1002835

34. Abdulai AA, Agana-Nsiire P, Biney F, Kwakye-Maclean C, KyeiFaried S, Amponsa-Achiano K, Simpson SV, Bonsu G, Ohene SA, Ampofo WK, Adu-Sarkodie Y, Addo KK, Chi KH, Danavall D, Chen CY, Pillay A, Sanz S, Tun Y, Mitjà O, Asiedu KB, Ballard RC (2018) Community-based mass treatment with azithromycin for the elimination of yaws in Ghana-results of a pilot study. PLoS Negl Trop Dis 12:e006303

35. El Hennawi DED, Geneid A, Zaher S et al (2017) Management of recurrent tonsillitis in children. Am J Otolaryngol 38:371-374

36. Murphy TK, Brennan EM, Johnco C, Parker-Athill EC, Miladinovic B, Storch EA, Lewin AB (2017) A double-blind randomized placebo-controlled pilot study of azithromycin in youth with acute-onset obsessive-compulsive disorder. J Child Adolesc Psychopharmacol 27:640-651

37. Mayer-Hamblett N, Retsch-Bogart G, Kloster M, Accurso F, Rosenfeld M, Albers G, Black P, Brown P, Cairns AM, Davis SD, Graff GR, Kerby GS, Orenstein D, Buckingham R, Ramsey BW, Retsch-Bogart G, Accurso FJ, Buckingham R, Howenstine M, Jacob S, Kronmal R, Kuhn R, Mayer-Hamblett N, McCoy K, Nichols D, Ramsey BW, Rosenfeld M, Sagel S, Saiman L, Sheridan J, Wilfond B, Zemanick E, Bondick I, Braam L, Brassil M, Buckingham R, Cianciola M, Heltshe S, Jacob S, Johnson M, Kirihara J, Kloster M, Kong A, Ma S, McNamara S, Mann L, 
Moormann K, Myers M, Mayer-Hamblett N, Ramsey BW, RetschBogart G, Seidel K, Skalland M, Ufret-Vincenty C, VanDalfsen J, Goss CH, Horne DJ, Kross EK, Leary PJ, Ramos KJ, Roush P, Salerno JC, Omlor G, Ouellette D, Green D, Hosler K, Savant A, Ashrafi Z, Berlinski A, Ross A, Sawicki G, Fowler R, Ulles M, Albers G, Branch F, Kirchner K, DiBenardo K, Kerby G, Anthony M, Keens T, Franquez A, Reyes C, Abdulhamid I, van Wagnen C, Orenstein D, Hartigan E, Mihlo C, Williams R, Lessard M, Sass L, McAndrews E, Parrott J, Noe J, Hastings P, Kump T, Clancy J, Niehaus S, Saiman L, Zhou J, Mueller G, Bartosik S, Fullmer J, Millian C, Stecenko A, Dangerfield J, Graff G, Kitch D, Cairns AM, Milliard C, Zanni R, Marra B, McCoy K, Guittar P, Smith M, Schaeffer D, DeLuca E, Welter J, Gallagher M, Ramirez A, Cornell A, Simeon E, Roberts D, Nelson K, Chmiel J, Schaefer C, Davis SD, Shively L, Wallace J, Richter A, Ramsey B, McNamara S, Pittman J, Hicks T, Brown P, Durham D, Milla C, Zirbes J, Fortner C, Suttmore V, Black P, Thompson R, Daines C, Varela M, Starner T, Teresi M, Nasr S, Kruse D, Thomas H, Houdesheldt L, Retsch-Bogart G, Barlow C, Cunnion R, Srinivasan S, Horobetz C, Asfour F, Francis J, Rock M, Makholm L, Egan M, Guzman C (2018) Azithromycin for early pseudomonas infection in cystic fibrosis the OPTIMIZE randomized trial. Am J Respir Crit Care Med 198:1177-1187

38. Mandhane PJ, de Silbernagel PPZ, Aung YN et al (2017) Treatment of preschool children presenting to the emergency department with wheeze with azithromycin: a placebo-controlled randomized trial. PLoS One 12:e182411

39. Levine A, Kori M, Kierkus J, Sigall Boneh R, Sladek M, Escher JC, Wine E, Yerushalmi B, Amil Dias J, Shaoul R, Veereman Wauters G, Boaz M, Abitbol G, Bousvaros A, Turner D (2019) Azithromycin and metronidazole versus metronidazole-based therapy for the induction of remission in mild to moderate paediatric Crohn's disease: a randomised controlled trial. Gut 68:239-247

40. Liu S, Zheng Y, Wu X, Xu B, Liu X, Feng G, Sun L, Shen C, Li J, Tang B, Jacqz-Aigrain E, Zhao W, Shen A (2018) Early target attainment of azithromycin therapy in children with lower respiratory tract infections. J Antimicrob Chemother 73:2846-2850

41. Valery PC, Morris PS, Byrnes CA, Grimwood K, Torzillo PJ, Bauert PA, Masters IB, Diaz A, McCallum GB, Mobberley C, Tjhung I, Hare KM, Ware RS, Chang AB (2013) Long-term azithromycin for indigenous children with non-cystic-fibrosis bronchiectasis or chronic suppurative lung disease (Bronchiectasis Intervention Study): a multicentre, double-blind, randomised controlled trial. Lancet Respir Med 1:610-620
42. Tilelli JA, Smith KM, Pettignano R (2006) Life-threatening bradyarrhythmia after massive azithromycin overdose. Pharmacotherapy 26:147-150

43. Eberly MD, Eide MB, Thompson JL, Nylund CM (2015) Azithromycin in early infancy and pyloric stenosis. Pediatrics $135: 483-488$

44. Anderson M, Choonara I (2010) A systematic review of safety monitoring and drug toxicity in published randomised controlled trials of antiepileptic drugs in children over a 10-year period. Arch Dis Child 95:731-738

45. de Vries TW, van Roon EN (2010) Low quality of reporting adverse drug reactions in paediatric randomised controlled trials. Arch Dis Child 95:1023-1026

46. Oldenburg CE, Arzika AM, Amza A, Gebre T, Kalua K, Mrango Z, Cotter SY, West SK, Bailey RL, Emerson PM, O’Brien KS, Porco TC, Keenan JD, Lietman TM (2019) Mass azithromycin distribution to prevent childhood mortality: a pooled analysis of clusterrandomized trials. Am J Trop Med Hyg 100:691-695

47. SanFilippo A (1976) Infantile hypertrophic pyloric stenosis related to ingestion of erythromycine estolate: a report of five cases. J Pediatr Surg 11:177-180

48. Stang H (1986) Pyloric stenosis associated with erythromycin ingested through breastmilk. Minn Med 69:669-670 82

49. Centers for Disease Control and Prevention (CDC) (1999) Hypertrophic pyloric stenosis in infants following pertussis prophylaxis with erythromycin-Knoxville, Tennessee. MMWR Morb Mortal Wkly Rep 48:1117-1120

50. Honein MA, Paulozzi LJ, Himelright IM, Lee B, Cragan JD, Patterson L, Correa A, Hall S, Erickson JD (1999) Infantile hypertrophic pyloric stenosis after pertussis prophylaxis with erythromcyin: a case review and cohort study. Lancet 354:21012105

51. Mahon BE, Rosenman MB, Kleiman MB (2001) Maternal and infant use of erythromycin and other macrolide antibiotics as risk factors for infantile hypertrophic pyloric stenosis. J Pediatr 139: 380-384

52. Cooper WO, Griffin MR, Arbogast P, Hickson GB, Gautam S, Ray WA (2002) Very early exposure to erythromycin and infantile hypertrophic pyloric stenosis. Arch Pediatr Adolesc Med 156:647650

Publisher's note Springer Nature remains neutral with regard to jurisdictional claims in published maps and institutional affiliations. 